\title{
The virtual design and simulation of gypsum block molding machine
}

\author{
Yang $\mathrm{Gao}^{1, \mathrm{a}}$, Yumin $\mathrm{He}^{1, \mathrm{~b}}$ Baohui Zhu ${ }^{1, \mathrm{c}}$ and Wanying Cheng ${ }^{1, \mathrm{~d}}$ \\ ${ }^{1}$ Xi'an university of architecture and technology,Xi'an710055, China; \\ agaoym09@163.com, bhe_yumin@163.com, c244960547@qq.com, d641380673@qq.com
}

Keywords: Gypsum block molding machine, virtual design, simulation

\begin{abstract}
In this paper, the model-box system and demolding mechanism of gypsum block molding machine are designed using 3D modeling software. Then the movement simulation of gypsum block molding machine is completed. This is helpful to shorten the design period and improve the performance of product.
\end{abstract}

\section{Introduction}

Gypsum hollow block is a building material with good properties. It has the characteristics of fire prevenion, heat insulation, high strength, also has the advantages of energy-saving, light weight, high construction quality and so on.

Molding machine performance directly affect the production efficiency of gypsum block, therefore, the optimization and improvement of the gypsum block molding machine has become a hot research topic. Singh.M[1] prospected the development of gypsum materials in India and other developing countries and developed countries in the future.Zou[2] et al,studied the strength and crack behavior under high strain rate.Huang Shoubing [3] et al introduced the basic properties and functions of gypsum block, and summarized the development status of the domestic and international.Tesarek.P[4],et al studied the strength of gypsum block and elastic modulus was affected by the weather factors. A continuous molding machine, which can produce gypsum block was developed by Li Changchun[5] and Cui Huanyong in 2001,. Gao Yatian [6] summarized the molding machine development of Beijing liboter gypsum block, and pointed out the development direction of molding machine.Gao Chenghui [7] et al,used SolidWorks as a platform establish the 3D model of the gypsum block molding machine by the Parametric design method and motion simulation function, and realized the virtual assembly design and Simulation of the molding machine. On the basis of the existing SG-2 molding machine, Luo Xianbing [8] improved and perfected the structure of the part of the structure. The SG-AI type molding machine has been designed. Jiangsu Institute of architectural science has studied a variety of gypsum block molding equipments, including SD110 type of manual vertical core molding machine, SD90 type of manual group core pulling machine, etc[9].In this paper, we realize the 3D virtual design and simulation of molding machine by 3D software.

\section{The virtual design of model-box system}

Now we design a kind of gypsum hollow block specifications: $500 \mathrm{~mm} \times 200 \mathrm{~mm} \times 314 \mathrm{~mm}$ ( The length of the gypsum block is $500 \mathrm{~mm}$, the width is $200 \mathrm{~mm}$, the height is $314 \mathrm{~mm}$ ) The model-box uses a mold with ten cavity structures, the box is equipped with 4 parallel plates, it is divided into 5 cavities. The model- box is made of 40Cr material, the surface of the core and its walls are coated with a chemical alloy layer to reduce friction between the block and the mold-box. The specific parameters of the model-box are as follows: model-box length $l_{1}=1450 \mathrm{~mm}$, width $b_{1}=1070 \mathrm{~mm}$, height $h_{1}=314 \mathrm{~mm}$, The length of the floor $l_{2}=1210 \mathrm{~mm}$, width $b_{2}=110 \mathrm{~mm}$, height $h_{2}=25 \mathrm{~mm}$. The model-box of 3D model is shown in figure 1 . 


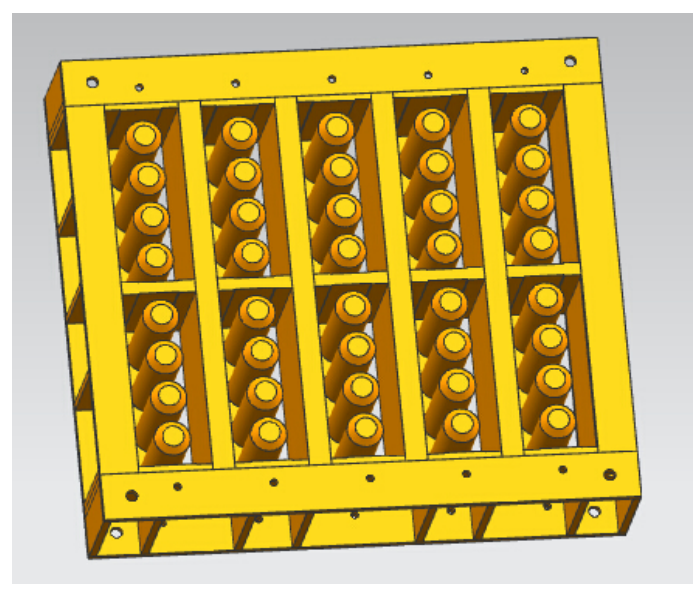

Fig.1 The 3D model of model-box

\section{The virtual design of demolding mechanism}

Because the mold uses ten cavity structures, for this we adopt 10 push plates, taking into account the balance problem of block, can be 4 push rods through the screw connection, the symmetry is fixed on each push plate, so we need 40 push rods totally. Through the theoretical calculation of each box clapboard the distance between the floor and mode is $45 \mathrm{~mm}$, So we will design each rod diameter $30 \mathrm{~mm}$, both ends with the prefabricated thread, one end connected with the push plate, and the other end of the connection with the following plate。The 3D design of demolding mechanism is shown in figure 2 :

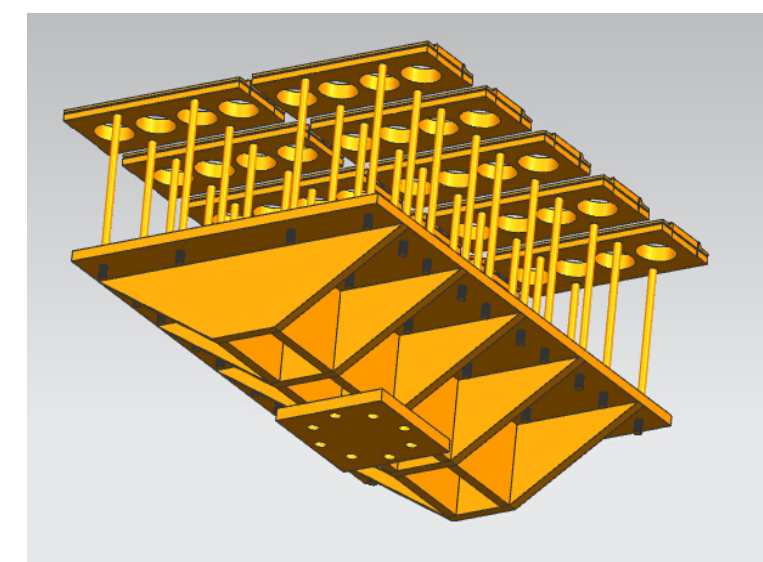

Fig.2 The 3D model of demolding mechanism

\section{The simulation of gypsum block molding machine}

We import the model into simulation module in UG, can proceed to the corresponding simulation analysis. The model of the assembly of a gypsum block molding machine is shown in figure 3. However, the motion analysis program is key to motion simulation, it includes creating connecting rod, kinematic pair and defining motion driving. The bearing and model-box are defined as fixed links, push rod and connected to them are defined as the movable links, solution is presented by using Step function to get the time- displacement diagram of demolding mechanism simulation, which is shown in figure 4: 


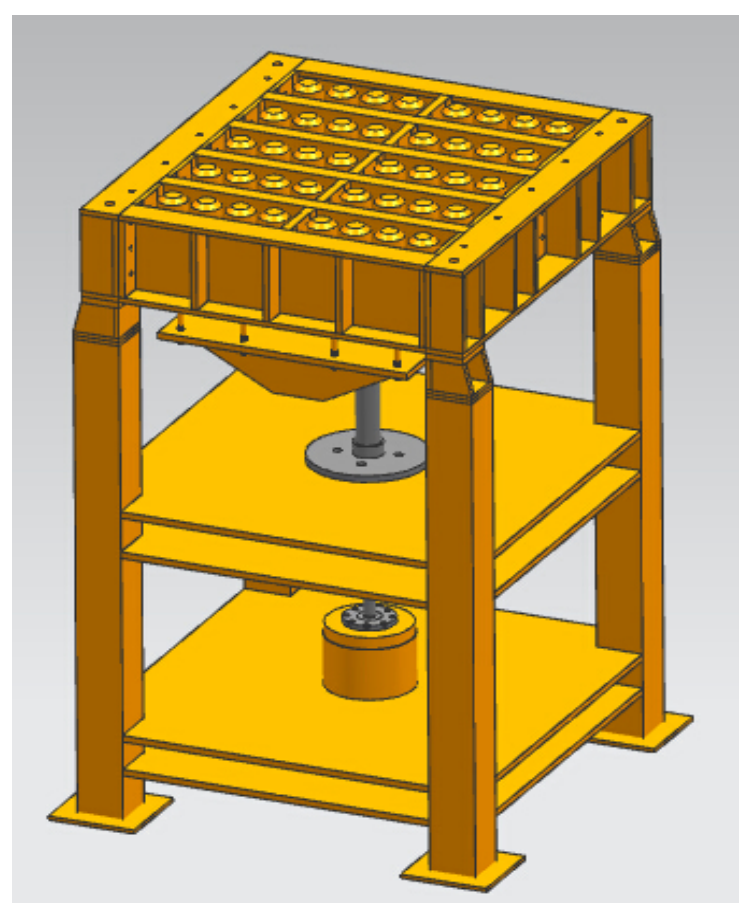

Fig.3 The model of gypsum block molding machine

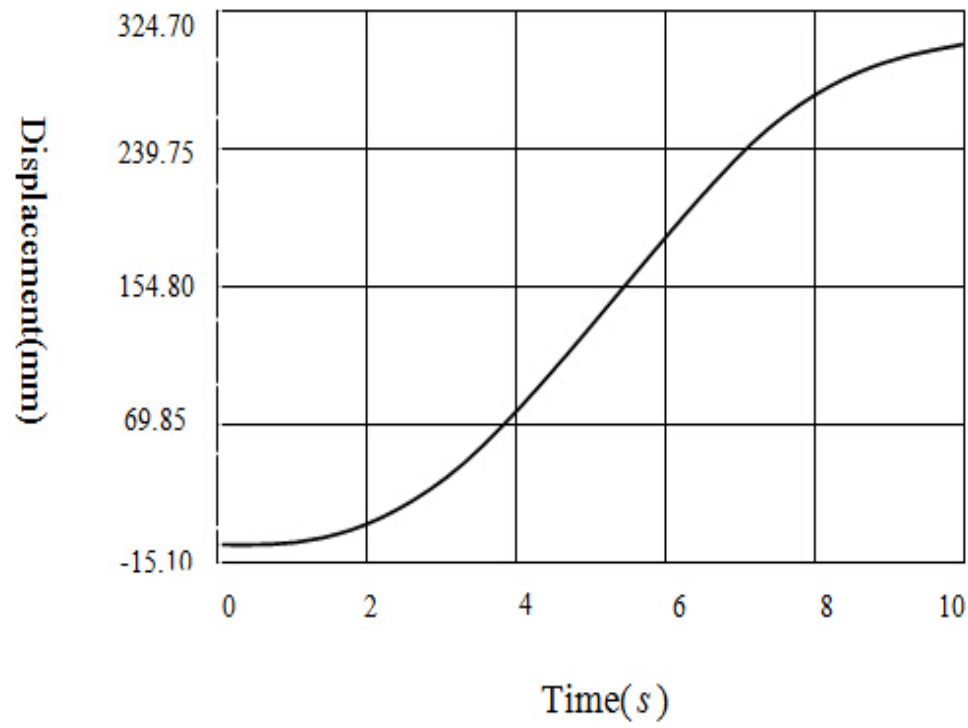

Fig.4 The time-displacement diagram of demolding mechanism simulation

Seen from figure 4,the gypsum block is pushed out from model-box spends $10 \mathrm{~s}$, and the distance is $314 \mathrm{~mm}$, the virtual simulation is proved right.

\section{Summary}

In this paper, combining with the working principle of the machine, we creat the molding box system and demolding mechanism by 3D software .The 3D virtual design and motion simulation of gypsum block molding machine is achieved and it is proved reasonable.

\section{Acknowledgment}

The authors acknowledge the financial support from Natural Science Foundation of Shanxi Province (No. 2014JM7269). 


\section{References}

[1].Singh, Manjit.Global trends in gypsum industry. Indian Concrete Journal,Vol. 85 (2011), p. 4960 .

[2].Zou Chunjiang,Wong Louis Ngai yuen,Cheng,Yi. The strength and crack behavior of the rocklike gypsum under high strain rate. 46th US Rock Mechanics / Geomechanics Symposium,Vol. 3 (2012), p. 1773-1786.

[3].Huang Shoubing,Tang Kai, Miu Jianbo.The development and prospect of gypsum block.Sichuan construction,Vol. 34 (2014), p. 227-230.

[4].Tesarek Pavel,Mracek Toma,Padevet Pavel:Material properties of a gypsum block exposed to influence of weather. 48th International Scientific Conference on Experimental Stress Analysis.(2010), p. 427-430.

[5].Li Changchun,Cui Huanyong.The research on continuously gypsum molding machine.Chinese building materials and equlpments.(2001), p. 32-33.

[6].Gao Yatian.The research on the intelligent control of Beijing libert gypsum hollow block machine. Machinery and equipment. (2006) No. 2, p. 53-54.

[7].Gao Chenghui,Zhang Xiangyu,Wang Huaxiang.The 3D design of gypsum hollow block molding machine based on SolidWorks. Computer application technology,Vol. 38 (2010) No. 9, p. 44-50.

[8].Luo Xianbing.The design and hydraulic system of a new type of gypsum block molding machine. Wuhan University of Science and Technology.(2009).

[9].Zhan Xiaotian.Development of the equipment of gypsum block molding machine. Jiangsu Institute of Architectural Science. (1995) No. 2, p. 46-48. 